\title{
A statistical model for antibody-antigen binding
}

\author{
S.Katletz, U.M.Titulaer \\ Institute for Theoretical Physics, Johannes Kepler University \\ Altenbergerstrasse 69, Linz, Austria
}

Received July 6, 1998

We discuss a statistical model for antibody-antigen binding. The two macromolecules are assumed to be linked by a number of relatively weak bonds (or groups of correlated bonds) that are assumed to open and close statistically. We use the model for a preliminary analysis of experiments performed in the Institute of Biophysics at the Johannes Kepler University. In these experiments the two molecules are brought into contact using an atomic force microscope; then a prescribed time dependent force is applied to the bond and the distribution of times needed to pull the molecules completely apart is measured. This quantity is calculated with our model; its dependence on the model parameters (binding free energies, number of groups of correlated elementary bonds, force dependence of the binding free energy) is determined.

Key words: random walk, one step process, first passage time, dissociation time, antibody-antigen binding

PACS: 87.15.B, 87.80, 82.20.M, 05.20, 05.40

\section{Chemical reaction as a random walk with absorbing barrier}

In equilibrium statistical physics, the mass action law gives a relation between the reaction rates and the concentrations of reactants and products in a chemical reaction. The equilibrium constant involved is a function of the free energy difference between initial and final states and the temperature alone. This theory, however, cannot predict the kinetics of a reaction, since that is determined by the reaction path and by the potential energy barrier between the equilibrium states. Therefore one has to use non-equilibrium thermodynamics and introduce a model for the reaction in order to calculate the dissociation rate.

Montroll and Shuler[1] investigated a model for an uni-molecular reaction of the type

$$
\begin{aligned}
\mathrm{M}+\mathrm{AB} & \rightleftharpoons \mathrm{M}+\mathrm{AB}^{*}, \\
\mathrm{AB}^{*} & \longrightarrow \mathrm{A}+\mathrm{B},
\end{aligned}
$$




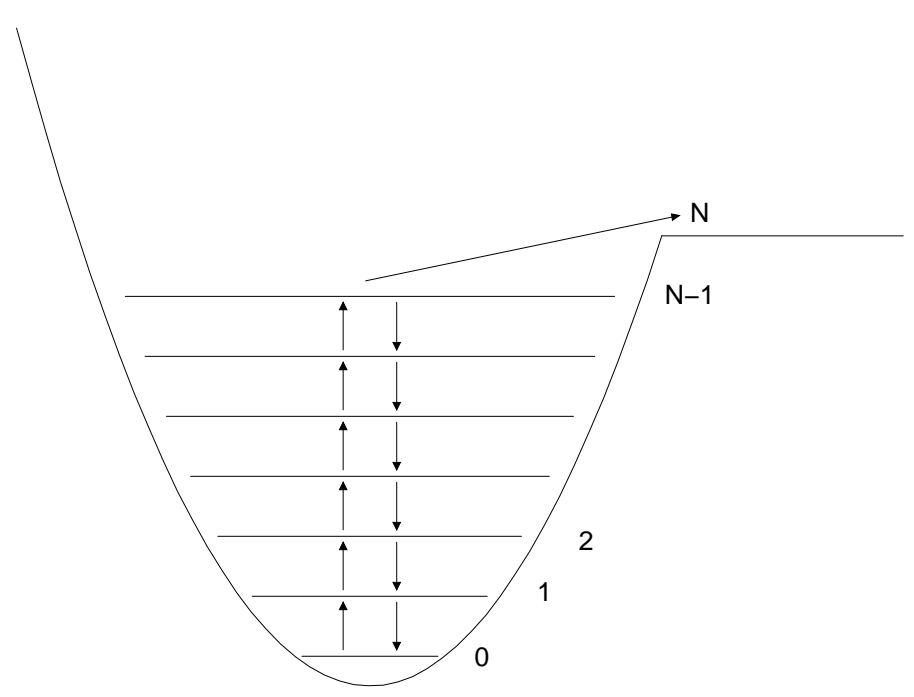

Figure 1. Potential energy and energy levels

where $M$ represents the heat bath molecules (the solvent), $A B$ the reactant molecules, $A B^{*}$ in their excited states and $A+B$ the dissociation products. They assumed that the potential energy between the molecules $A$ and $B$ is harmonic, the energy states are therefore $E_{n}=h \nu\left(n+\frac{1}{2}\right)$. During the collision between the solvent and reactant molecules energy is transferred and transitions between the energy states occur (see figure 1). Now an absorbing barrier is introduced, i.e. when a molecule $A B^{*}$ reaches the $\mathrm{N}$-th energy state it dissociates and is removed (there are no back reactions).

We denote by $x_{n}$ the probability that a molecule is in the $\mathbf{n}$ th state. This quantity obeys the master equation

$$
\begin{aligned}
\frac{\mathrm{d} x_{n}}{\mathrm{~d} t} & =\sum_{m} W_{n m} x_{m}-W_{m n} x_{n} \\
& =\sum_{m}\left[W_{n m}-\delta_{n m} \sum_{l} W_{l n}\right] x_{m} \\
& =\sum_{m} A_{n m} x_{m}
\end{aligned}
$$

with

$$
A_{n m}=W_{n m}-\delta_{n m} \sum_{l} W_{l n}
$$

$W_{n m}$ is the transition probability per unit time for a transition from level $\mathrm{m}$ to $\mathrm{n}$. In the original model, quantum mechanical perturbation theory for a harmonic oscillator in a heat bath yields the expression

$$
\begin{aligned}
& W_{n, n+1}=\mathrm{e}^{\beta E_{n+1}}(n+1) W_{0,1}, \\
& W_{n+1, n}=\mathrm{e}^{\beta E_{n}}(n+1) W_{0,1} .
\end{aligned}
$$

Note that only nearest neighbour transition can occur; we therefore have a one-step Markov process. 
We want to describe the dissociation of biomolecules, a reaction where a large number of small bonds must be broken. We identify the number $N$ with the number of bonds (not necessarily the total number of bonds in the case that a certain number of bonds form a group and can only open and close collectively - then $N$ is the number of groups). $E_{N}$ is the dissociation energy and the subscript $n$ becomes the number of open bonds (in the ground state 0 , in the dissociated state the total number of bonds or groups). Therefore we have to modify the transition probabilities: the probability that a bond is reestablished, $W_{n, n+1}$ is proportional to the number of open bonds, $W_{n+1, n}$, the probability that a bond breaks, proportional to the number of closed bonds. Allowing for an external force we are led to the following transition probabilities:

$$
\begin{aligned}
& W_{n, n+1}=\mathrm{e}^{\beta\left(E_{n+1}+\frac{F \lambda}{N-n-1}\right)}(n+1) W_{0,1}, \\
& W_{n+1, n}=\mathrm{e}^{\beta\left(E_{n}+\frac{F \lambda}{N-n}\right)}(N-n) W_{0,1} .
\end{aligned}
$$

$F$ is the total force trying to tear the molecule $A B$ apart and is assumed to be equally distributed over the bonds or groups of bonds; $\lambda$ is the proportionality constant in the dependence of the free energy on the force.

Note that by (5) detailed balance is satisfied when taking the degeneracy of each state into account:

$$
g_{m} W_{n m} x_{m}^{\mathrm{e}}=g_{n} W_{m n} x_{n}^{\mathrm{e}}
$$

with $g_{n}=\left(\begin{array}{l}N \\ n\end{array}\right)$ and $x_{n}^{\mathrm{e}}$ the probability distribution in equilibrium

$$
x_{n}^{\mathrm{e}} \propto \mathrm{e}^{-\beta\left(E_{n}+\frac{F \lambda}{N-n}\right)} .
$$

The first passage time is the time a molecule needs to reach the absorbing barrier for the first time. The distribution of the first passage times is proportional to the number of molecules passing this barrier at a certain time and is given by

$$
p(t)=W_{N, N-1} x_{N-1}(t) .
$$

\section{Numerical solution}

First we transform the matrix of our system of differential equations into a symmetrical one. The transformation

$$
x_{i}=b_{i} y_{i}
$$

with constant coefficients $b_{i}$ yields the recurrence relation

$$
b_{i}=\sqrt{\frac{a_{i, i-1}}{a_{i-1, i}}} b_{i-1} .
$$

We choose $b_{0}=1$; the elements of $\mathbf{B}$ are then given by

$$
B_{i, i-1}=a_{i, i-1} \frac{b_{i-1}}{b_{i}}=\sqrt{a_{i-1, i} a_{i, i-1}},
$$


which is obviously symmetric. The solution of the new system of differential equations is given by

$$
\vec{y}(t)=\sum \alpha_{i} \vec{\xi}_{i} \mathrm{e}^{\lambda_{i} t}
$$

where $\vec{\xi}_{i}$ is the eigenvector to the eigenvalue $\lambda_{i}$ satisfying

$$
\mathbf{B} \cdot \vec{\xi}_{i}=\lambda_{i} \vec{\xi}_{i}
$$

The eigenvectors $\vec{\xi}_{i}$ are orthogonal and can be normalized. Then the linear coefficients $\alpha_{i}$ are determined by the initial values of $\vec{x}$ and hence $\vec{y}$ :

$$
\begin{aligned}
\vec{y}(0) & =\sum \alpha_{i} \vec{\xi}_{i} \\
\alpha_{i} & =\vec{y}(0) \cdot \vec{\xi}_{i}
\end{aligned}
$$

As an initial distribution we choose the Boltzmann distribution,

$$
x_{n}(0)=\frac{\exp \left(-E_{n} / k_{\mathrm{B}} T\right)}{\sum \exp \left(-E_{n} / k_{\mathrm{B}} T\right)} .
$$

Using (8), the distribution of first passage times is given by

$$
\begin{aligned}
p(t) & =W_{N, N-1} b_{N-1} y_{N-1}(t) \\
& =W_{N, N-1} b_{N-1} \sum \alpha_{i} \xi_{i[N-1]} \mathrm{e}^{\lambda_{i} t}
\end{aligned}
$$

where $\xi_{i[N-1]}$ denotes the $N-1$ th component of $\vec{\xi}_{i}$.

In case of a time dependent force, (12) is applied for small time interval $\Delta t$ during which the force can be assumed to be constant. The solution $\vec{y}(t+\Delta t)$ is taken as the new initial value with a new force and a new transition matrix $\mathbf{B}$.

\subsection{Zero force}

The method described above was used to solve the differential equation for various total energies $E_{N}$ and total number of bond groups $N$. The mean first passage time when there is no force

$$
\tau_{0}=\int p(t) t \mathrm{~d} t
$$

corresponds to the inverse of the dissociation rate $1 / k_{\text {off }}$ which was measured experimentally [2]. Thus the factor $W_{01}$ can be determined.

\subsection{Constant force}

Figure 3 shows the ratio $\tau / \tau_{0}$ of mean first passage times. Its dependence on the number of bonds and on the applied force is shown. The mean first passage time decreases exponentially with the applied force, a slope being determined by the total number of bonds. 


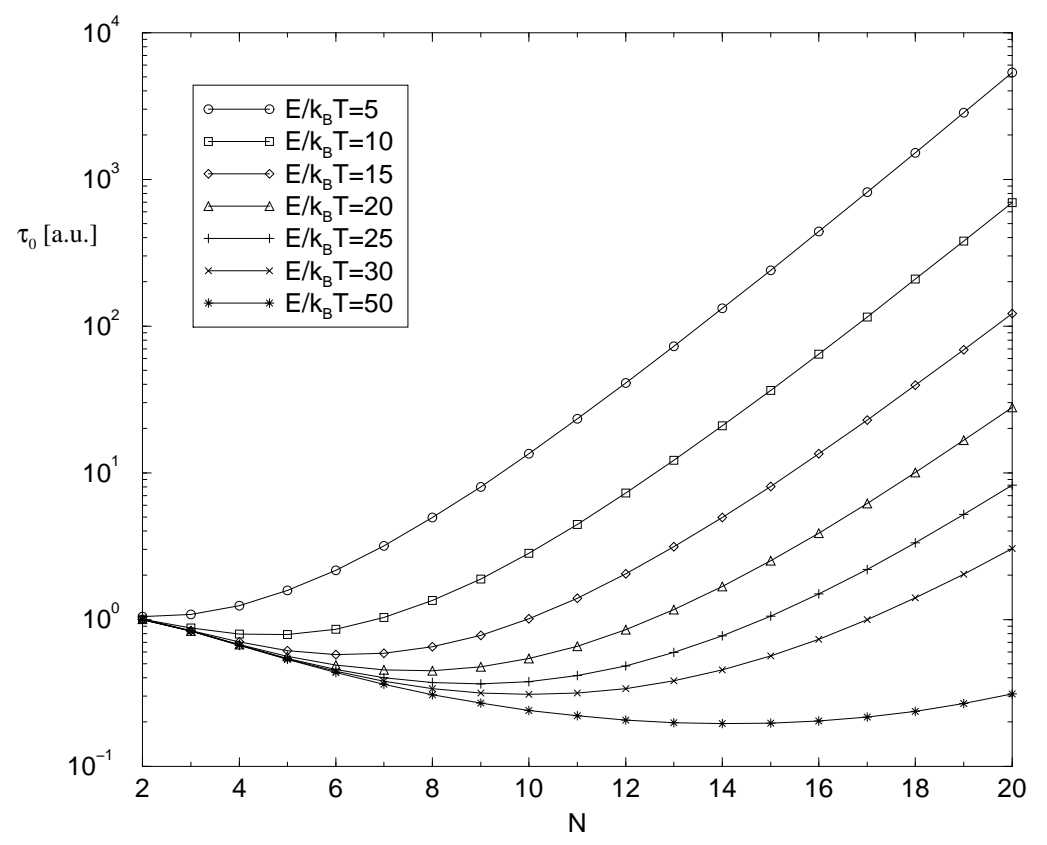

Figure 2. $\tau_{0}$ as a function of $\mathrm{N}$ and $E / k_{\mathrm{B}} T$
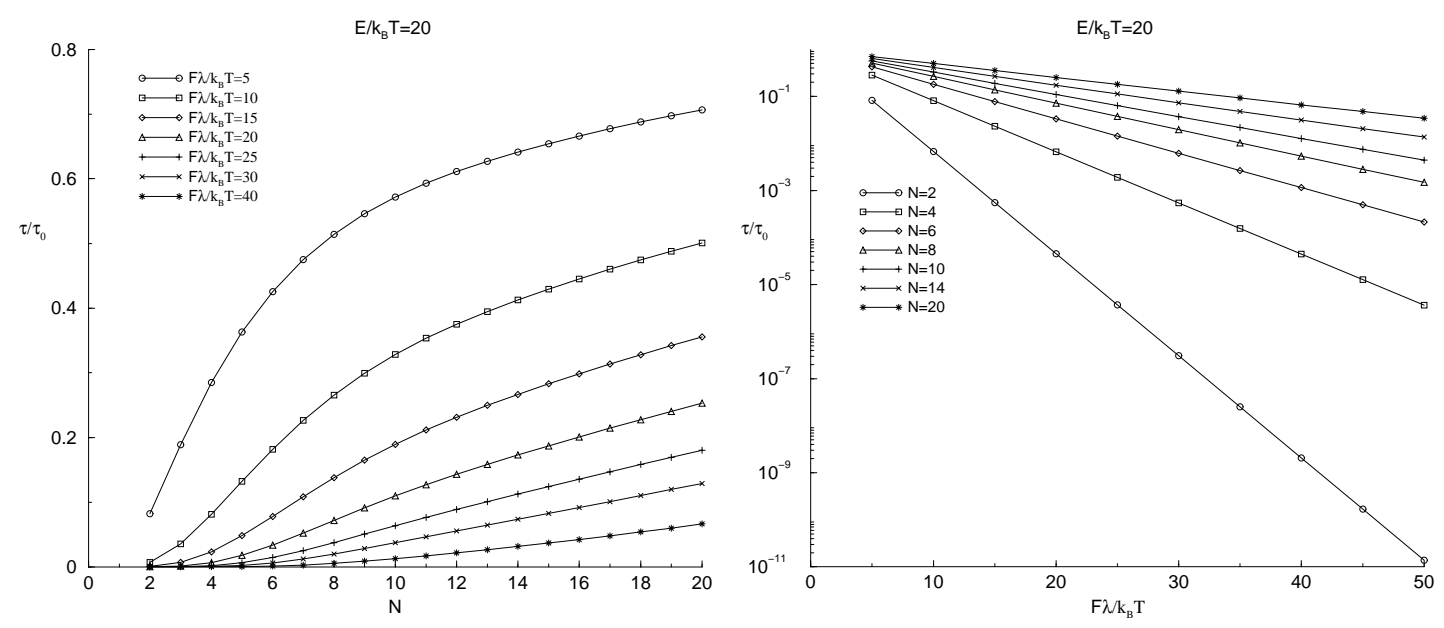

Figure 3. The mean first passage time at constant forces 

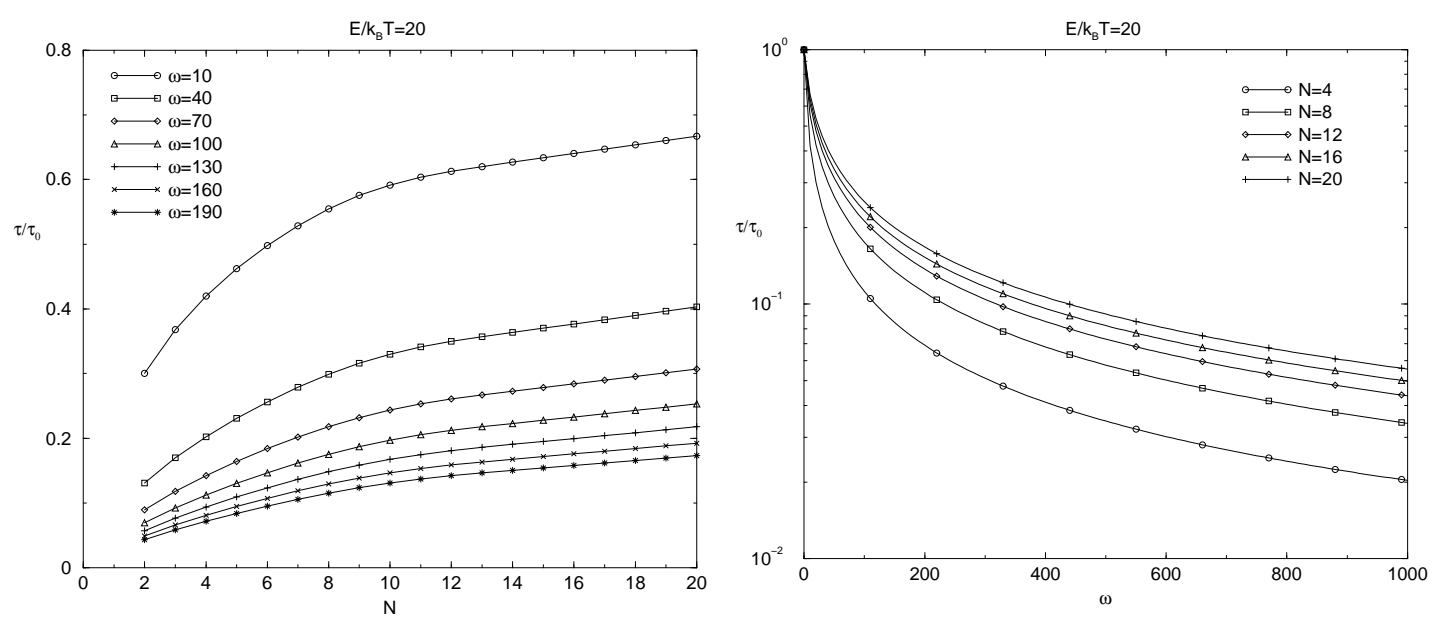

Figure 4. The mean first passage time at linearly increasing force

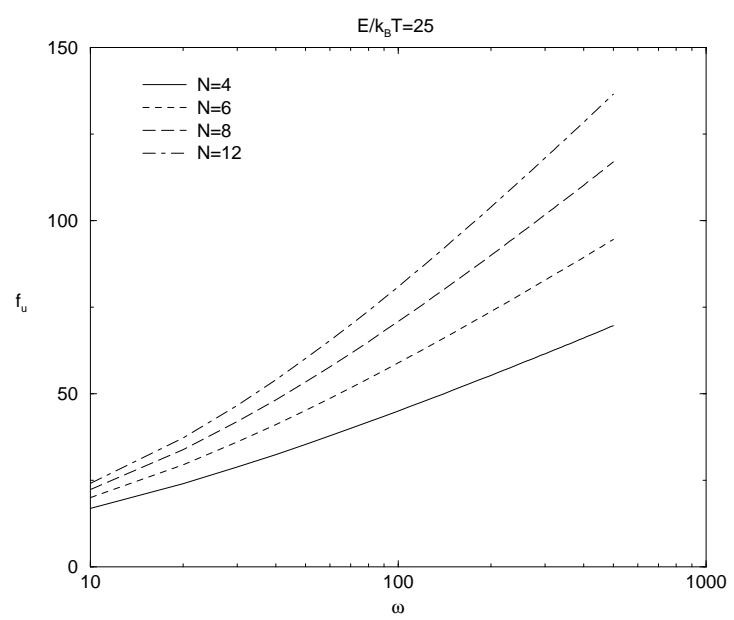

Figure 5. Mean rupture force



Figure 6. Distribution of rupture forces

\subsection{Linearly increasing force}

Finally a force varying according to

$$
\frac{F(t) \lambda}{k_{\mathrm{B}} T}=\omega \frac{t}{\tau_{0}}
$$

was inserted into the differential equation. Figure 4 shows the dependence of the mean first passage time on the total number of bonds and the pulling velocity.

We are also able to identify the distribution of rupture forces with the distribution of first passage times if we draw $F(t)$ instead of $t$. Furthermore we can compare these results with the experiments performed at the Institute of Biophysics at the University of Linz $[3,4]$.

Figure 5 shows that the mean rupture force increases roughly logarithmically with the pulling velocity, a fact also observed in the experiments. The slope is 
determined by the number of groups.

Finally we tried to fit the experimental rupture force distributions (antibody HyHel 8, cantilever with spring constant $30 \mathrm{pN} / \mathrm{nm}$, scanning frequency $3 \mathrm{~Hz}$ ) with our model as shown in figure 6 . With our choice of $\lambda=1.2 \mathrm{~nm}$ and $\omega=300$ the system with 4 groups seems to fit the data best.

\section{Conclusions}

Though there is still some disagreement between experimental and theoretical distributions of the rupture force, the dependence of the mean rupture force on the pulling velocity shows that the model is capable of describing the experiment on the right time scale. The difference may be due to the nonlinear increase of the force that actually acted on the binding [5]. In a further investigation this nonlinear force increase will be used, allowing a better way of determining the force constant $\lambda$.

Another modification that will be necessary is to relax the condition that a group of bonds open or close together instantaneously. Although a high degree of correlation is plausible on biophysical grounds, a complete correlation is certainly too rough an approximation to obtain quantitative agreement with the experiments.

Acknowledgements: It is a pleasure to thank Prof. Hansgeorg Schindler, Dr. Peter Hinterdorfer and Ms Anneliese Raab (Institute of Biophysics) for very fruitful discussions.

\section{References}

1. Montroll E.W., Shuler K.E. The application of the theory of stochastic processes to chemical kinetics. Advances in Chemical Physics 1 (I. Prigogine ed., Interscience, New York 1958), p. 361-399.

2. Mohan S., Smith-Gill S.J. Conformational flexibility and cognitive properties of crossreactive high affinity antibodies. // to be published.

3. Hinterdorfer P., Baumgartner W., Gruber H.J., Schilcher K., Schindler H. Detection and localization of individual antibody-antigen recognition events by atomic force microscopy. // Proc. Natl. Acad. Sci. USA, 1996, vol. 93, p. 3477-3481.

4. Hinterdorfer P., Raab A., Badt D., Smith-Gill S.J., Schindler H. Force spectroscopy of antibody-antigen recognition measured by scanning force microscopy. // Biophys. J., 1998, vol. 74 (2), p. A 186.

5. The force vs. extension dependence of the spacer molecule PEG, which connects the antibody to the cantilever of the AFM, agrees very well with the freely joint chain model. In this model the extension is given by the Langevin equation plus a linear dependence due to the cantilever.

$$
x=N l\left(\operatorname{coth} \frac{F L}{k_{\mathrm{B}} T}-\frac{k_{\mathrm{B}} T}{F L}\right)+\frac{F}{k}
$$

$L$ is the Kuhn length, $\mathrm{Nl}$ the contour length of the polymer, $k$ the spring constant of the cantilever. See for example: Eyring H., Henderson D., Jones Stover B., Eyring E.M. Statistical Mechanics and Dynamics. New York, John Wiley \& Sons, 1964. 


\section{Статистична модель зв'язування антитіло-антиген}

\section{С.Катлєц, У.Тітуляр}

Інститут теоретичної фізики, Університет Йогана Кеплера Австрія, Лінц, Алтенбергштрассе, 69

\section{Отримано 6 липня 1998 р.}

Обговорюється статистична модель, яка описує зв'язування антитіло-антиген. При цьому вважається, що дві макромолекули можуть поєднуватись через набір відносно слабих зв'язків (чи груп скорельованих зв'язків), що відкриваються і закриваються статистично. Ця модель використовується для попереднього аналізу експериментів, виконаних в Інституті біофізики Університету Йогана Кеплера. У цих експериментах дві молекули приводились у контакт, використовуючи атомної сили мікроскоп, а потім прикладалася певна залежна від часу сила до зв'язку і вимірювався розподіл часів, необхідних для повного розділення молекул. Ця характеристика розраховується з використанням запропонованої моделі; знайдена її залежність від модельних параметрів (вільних енергій зв'язування, числа груп скорельованих елементарних зв'язків, залежності вільної енергії зв'язування від сили).

Ключові слова: вільні блукання, однокрокові процеси, час першої події, час дисоціації, антитіло-антиген зв'язування

PACS: $87.15 . B, 87.80,82.20 . M, 05.20,05.40$ 